\author{
Abstracta Iranica \\ Abstracta Iranica Revue bibliographique pour le domaine irano-aryen \\ Volume 37-38-39 | 2018 \\ Comptes rendus des publications de 2014-2016
}

\title{
Florence Jullien. « Le monachisme réformé en Mésopotamie (VIe siècle) : Identité et référence »
}

\section{Marie-Joseph Pierre}

\section{(2) OpenEdition}

\section{Journals}

Édition électronique

URL : http://journals.openedition.org/abstractairanica/42757

DOI : 10.4000/abstractairanica.42757

ISBN : 1961-960X

ISSN : 1961-960X

Éditeur :

CNRS (UMR 7528 Mondes iraniens et indiens), Éditions de l'IFRI

Référence électronique

Marie-Joseph Pierre, «Florence Jullien. « Le monachisme réformé en Mésopotamie (Vle siècle)

Identité et référence » ", Abstracta Iranica [En ligne], Volume 37-38-39 | 2018, document 7, mis en ligne le 10 mars 2018, consulté le 27 septembre 2020. URL : http://journals.openedition.org/ abstractairanica/42757 ; DOI : https://doi.org/10.4000/abstractairanica.42757

Ce document a été généré automatiquement le 27 septembre 2020

Tous droits réservés 


\title{
Florence Jullien. « Le monachisme réformé en Mésopotamie (VIe siècle) : Identité et référence »
}

\author{
Marie-Joseph Pierre
}

\section{RÉFÉRENCE}

Florence Jullien. « Le monachisme réformé en Mésopotamie (VIe siècle) : Identité et référence ", Les interactions chez les religieux (Antiquité tardive-fin du XIXe siècle). Emprunts, échanges et confrontations. Actes du VIIIe colloque international du CERCOR (Saint-Étienne, 24-26 octobre 2012), Saint-Étienne : PUSE, collection du CERCOR, 2015, p. 49-60.

1 L'ample mouvement de réforme du monachisme syro-oriental entreprise par Abraham de Kashkar au milieu du $\mathrm{VI}^{\mathrm{e}}$ siècle s'imposa progressivement jusqu'à structurer toute la culture monastique de l'Euphrate à l'Inde, et ainsi devenir l'expression de l'identité des chrétiens syro-orientaux face aux autres courants christologiques. L'A. examine les signes identitaires forts de cette appartenance confessionnelle, qui se traduisent par les realia de la vie monastique (vêtements distinctifs, tonsure, disposition architecturale spécifique) et par une organisation sur le terrain. 


\section{AUTEURS}

\section{MARIE-JOSEPH PIERRE}

Directrice d'Études honoraire, EPHE 